This item was submitted to Loughborough's Research Repository by the author.

Items in Figshare are protected by copyright, with all rights reserved, unless otherwise indicated.

\title{
Teaching ecological sanitation in a school environment in Zimbabwe
}

PLEASE CITE THE PUBLISHED VERSION

PUBLISHER

(c) WEDC, Loughborough University

VERSION

VoR (Version of Record)

\section{PUBLISHER STATEMENT}

This work is made available according to the conditions of the Creative Commons Attribution-NonCommercialNoDerivatives 4.0 International (CC BY-NC-ND 4.0) licence. Full details of this licence are available at: https://creativecommons.org/licenses/by-nc-nd/4.0/

\section{LICENCE}

CC BY-NC-ND 4.0

\section{REPOSITORY RECORD}

Shangwa, Annie, and Peter R. Morgan. 2019. "Teaching Ecological Sanitation in a School Environment in Zimbabwe”. figshare. https://hdl.handle.net/2134/30122. 
34th WEDC International Conference, Addis Ababa, Ethiopia, 2009

\author{
WATER, SANITATION AND HYGIENE: \\ SUSTAINABLE DEVELOPMENT AND MULTISECTORAL APPROACHES
}

\title{
Teaching ecological sanitation in a school environment in Zimbabwe
}

\author{
Annie Shangwa \& Peter R. Morgan, Harare, Zimbabwe
}

REVIEWED PAPER 232

\begin{abstract}
This paper reports on a pilot study being carried out at the Chisungu Primary School, Harare, Zimbabwe, where children are taught the basics of ecological sanitation and hygiene in class and then taught how to build a range of low cost toilets. These include toilets made from bricks. The range includes simple toilets like the Arborloo (tree toilet), and also various types of VIP (Ventilated improved pit toilet). The children themselves do the construction work. In addition the children are taught the value of applying urine to food crops like green vegetables and maize in experiments undertaken in the school garden. The project is an attempt to provide a very practical and hands on approach to teaching low cost sanitation, recycling and hygiene in an environment which has enormous potential for replication. The school, with its dedicated teaching staff and an enthusiastic younger generation is perhaps one of the most ideal learning centres and dissemination points for low cost sanitation that exist.
\end{abstract}

\section{Introduction}

The school environment is perhaps one of the best to teach the younger generation the importance of good hygiene, and the benefits of improved sanitation. The target audience at schools is enormous and widespread throughout every country. Teachers are committed professionals and the children enthusiastic and eager to learn new things and develop new skills. The school lies at the heart of every rural and urban community. The need for improved sanitation and water supplies is overwhelming, not only in family homesteads but also at schools. It seems logical therefore to place a training component for improved sanitation in the school itself. School curricular can be built around this need and the skills that form part of it. The technicalities of simple toilet construction, hand washing devises and even good water supplies can be taught in science classes and also in extra curricular activities.

The link to ecological sanitation, where recycling of the excreta is encouraged also fits well into this scheme, as it links the sanitation and water aspects of training into the huge disciplines of agriculture and forestry with the all the benefits that these can bring. The school garden is an ideal place for the learning process to take place.

This paper reports briefly on experimental work being undertaken at the Chisungu Primary School in a periurban settlement near Harare. The school children are taught the basics of good hygiene practice and sanitation and also how to build a range of simple yet effective toilets. These range from the Arborloo (tree toilet) to the Ventilated Improved Pit (VIP) toilet. The children are also taught how to build hand washing facilities, pedestals and even vent pipes. In addition, the benefits of using nitrogen derived from urine are taught in the school garden. Green vegetables and maize can benefit greatly by the addition of urine. The link between trees and toilets is taught by the planting of trees near to toilets or on top of filled pits. The roots gain nutrients from the digesting material in the ground.

\section{The school}

Chisungu Primary school was established in 1938 and has an enrolment of 2500 pupils. The pupils chosen for this activity were taken from grades 5 and 6, a total of about 20 in all, about half girls and half boys. The lessons taught are all extra - curricular activities. That is mostly out of normal school working hours. The 
headmaster has been assigned the responsibility of assigning selected children for the extra instruction and a dedicated teacher supports and assists with practical activities. The author of this paper, Mrs Annie Shangwa, is Project Manager and Trainer.

\section{The training schedule}

The schedule being used in this pilot programme follows the sequence laid out below. It starts by consent being given by the headmaster or headmistress for the extra curricular activities to take place. Suitable classes and teachers are chosen and then selected pupils who show interest and skills. The school provides bricks and sand etc, with other inputs (e.g. cement) being provided by the support agency. The training schedule is laid out as follows:

1. Lecture on importance of sanitation and hygiene including the concept of ecological sanitation and a description of the low cost toilet range

2. Training in the construction of a range of toilets in practice

3. Training and construction of hand washing facilities, pedestals and vent pipes etc

4. Training and demonstration of effectiveness of urine on the growth of vegetables and maize in the school garden

5. Planting trees linked to toilets

6. Promotion of an outreach programme to communities around the school.

This schedule is supported by training materials which include:

1. Flip charts

2. Models

3. Instructional manuals in English and local language (Shona)

4. Production of power points.

\section{The first lecture}

This is important as it carefully introduces the selected pupils to the realm of improved sanitation, personal hygiene and the concept and practice of ecological sanitation, where the world of toilets is linked to the world of plants, food and trees. A range of simple toilets are described and the methods of recycling toilet compost and also urine. Models are used to show the techniques in the classroom. The value of urine and toilet compost is also described. Urine is useful as it contains a lot of nitrogen which green vegetables and maize respond to very well. The first lecture in the class room also describes how to make simple yet effective hand washing devices.

\section{Toilet construction}

This takes place over a series of weeks or months as the school time schedule permits. The work undertaken is a form of extra curricular activity. The basics of concrete construction, brick laying and toilet house construction are taught. Also methods of making vent pipes (for use in VIP), pedestals and hand washing devices are taught.

The range of toilets built so far in these extra curricular activities include:

1. The simple Arborloo (tree toilet) which can be upgraded to a simple VIP. This uses a ring beam method to protect the shallow pit (Morgan, P.R. 2007)

2. The brick built VIP with a door with brick lined pit using corbelling technique (Photograph 1)

3. The brick built VIP with door- less spiral with brick lined pit using corbelling technique (Morgan, P.R. 1990).

The brick toilets are supported on a brick lined pit using a specialised "corbelling" technique of brick construction where the base of the pit is wider than the top, allowing for a smaller cost effective slab to be placed over a pit of large capacity. Methods of planting trees on the top of filled pits (Arborloo) and also to the side of filling pits are also taught. The construction of urine diverting pedestals and squat plates are also demonstrated. 


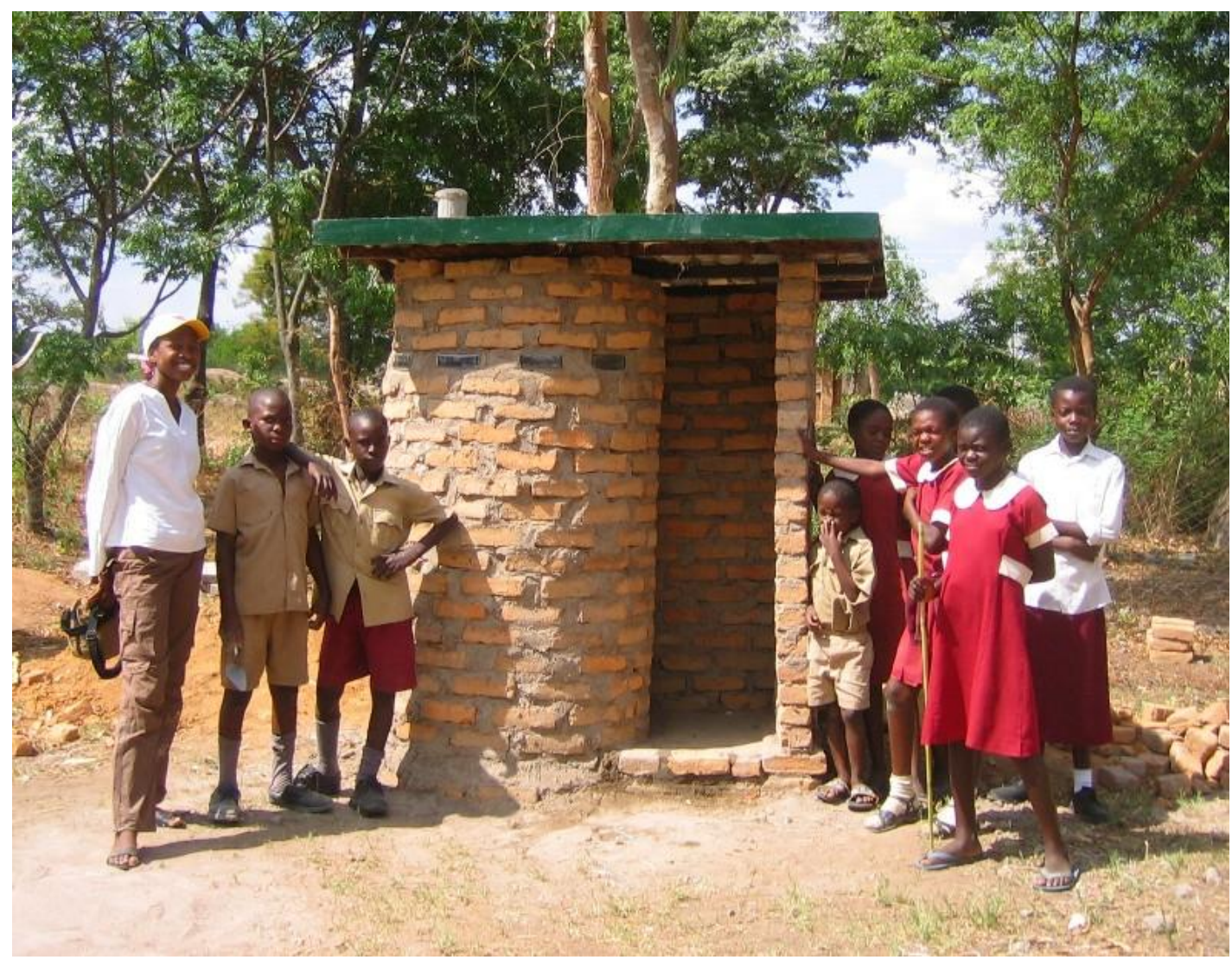

\section{Photograph 1.}

\section{Experiments in the school garden}

An important part of this educational programme includes experiments performed in the school garden where the effects of urine on green vegetables and maize are taught. The soil in the school garden is very poor, providing few nutrients for plants unless extra "fertilizer" is provided (Photograph 2). These experiments are performed in small simple gardens called "ring beam gardens" ( $1 \mathrm{~m}$ diameter round gardens) where the effects of diluted urine on various plants are demonstrated. Striking results can be obtained within a month using this technique. The plants used in the experiments so far include rape, spinach and maize. Leaf weight can be increased by 7 times for rape and by 4 times for spinach by the application of 3 litres of a 3:1 mix of water and urine, applied to the test ring beam garden three times a week.

A huge range of potentially valuable plants can be used in these simple garden experiments. Before the garden exercise begins, the children are given a background lecture on the principles and techniques involved. Then the work begins immediately. Chosen seedlings are planted and allowed to stabilise for a week in each ring beam garden before urine application begins. Urine is provided by the boys and is collected in bottles in the school toilet. This is diluted with water and applied to the "treated" ring beams, with a control in which the small garden is treated with water only. The effects are urine application are clearly visible within a month. This can make a stunning impact on the observers, such as teachers, parents and community members. 


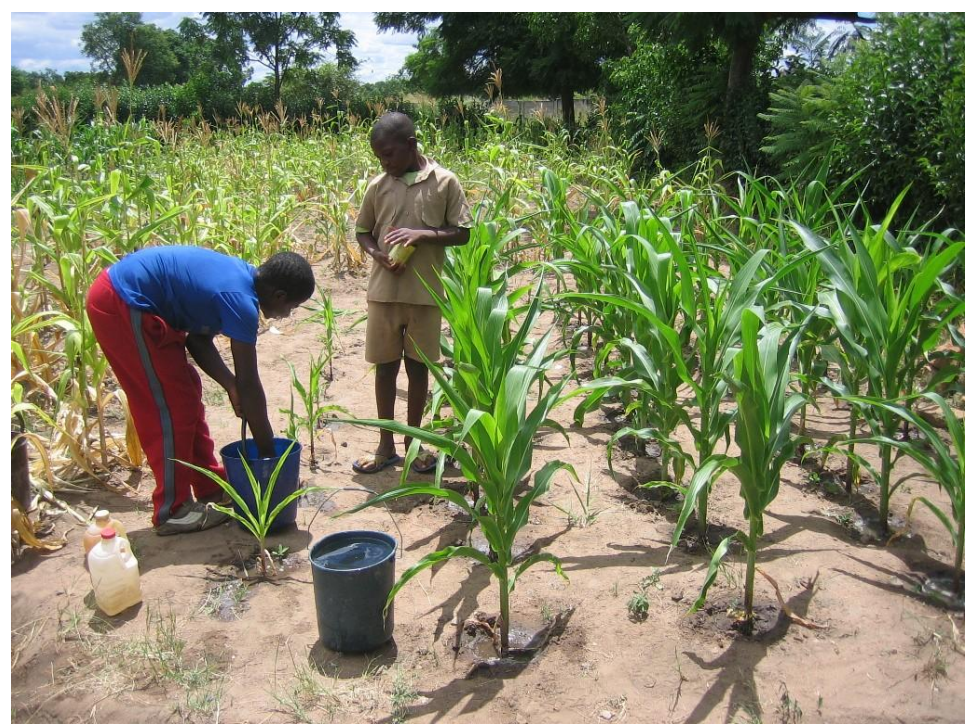

\section{Photograph 2.}

\section{Background experimental work}

Many of the toilet designs built and the plant trials carried out in the school are first tested in the "backyard environment" first, before the methods are taught and exposed to the school and community. This ensures that the end result can almost be guaranteed before the training is undertaken.

\section{Tree planting}

The tree plays an important role in linking the toilet to the world of plants. Most trees grow well when tapping the nutrients found in shallow pit toilet compost. Trees are a wonder's of Nature and can provide food in the form of fruit. Tree's can also provide fuel, shade, medicine and many other valuable commodities. The tree is able to convert the nutrients in excreta into valuable fruit which provide food and essential vitamins. Trees can also be planted near established pit toilets as they are filling. In the standard Arborloo the tree is planted in a generous layer of soil placed on top of the decomposing excreta once the pit is full. But it is also possible to plant the tree to the side of the toilet at the same time as it is built and put to use. The tree roots will eventually find the nutrients provided by the decomposing excreta.

\section{Open days}

These various toilets, garden experiments and tree planting can be a source of great pride for the children and even the school. The children build the toilets themselves under skilled supervision. The teachers lend a hand. This is a "hands on" operation. There is an active involvement by the participants. The activity is not passive - just listening - it is hands on and active. Concrete making, pit digging, brick construction and various other practical activities are undertaken. It is truly an exercise in "Learning by Doing."

\section{Outreach work}

The work under taken at the school by teachers and children can serve as good examples for the families living in the surrounding community who can be taught by their children and shown their own handiwork. Some children, even at primary school level have amazing abilities at building and artisan work. Brick construction is an example. Such skills are present in the communities even at a young age. This type of work exposes the skills acquired by some pupils at an early age. Others learn from the training direct.

\section{Ongoing work}

This pilot project is still underway. Many aspects are still to be investigated. These include:

1. Toilet for the "Girl child" where special low cost pedestals and hand washing facilities are provided 
2. Urinal for boys in which the urine is either collected in containers or tanks or directed to a nitrogen loving tree like a banana

3. Testing a variety of trees grown directly on Arborloo pits and also to the side of filling compost pits or deep pits

4. Important maize trials using urine in the school garden. This technical work has already been undertaken in the same peri-urban settlement (Epworth) and needs to be copied and refined for the school environment. It has already been established in earlier maize trials that grain output can be doubled by the application of urine alone as a "fertilizer" on poor sandy soils

5. The construction of various urine diversion pedestals and squat plates fitted to toilets.

\section{Training materials}

This comes in several forms:

1. Flip charts

2. Small models

3. Fact sheets (short precise documents on specific subjects)

4. Training manuals (including local language)

5. Power points (for use where facilities allow)

6. Book (in production).

\section{Summary and conclusions}

This work is being undertaken as a research and development exercise in a single school, with the intension of extending the method to other schools and locations once the techniques and training methods have been perfected. A great deal is being learned from this pilot programme as the training takes place. The translation of the methods from English into the local language (Shona, in this case) requires a skill not only in finding words to meet the English equivalent but also the interpretation of the meaning of the principles involved. The application of these methods adds to the already considerable work being carried out in schools by other workers. The work is linked to the safe provision of potable water, in this case a hand pump, known in Zimbabwe as the Bush Pump.

The work shows that by using simple methods and using skilled trainers and enthusiastic teachers and children, remarkable achievements are possible. If these skills and methods are passed on with enthusiasm to the generations of the future, there is no limit to what could be achieved in this area of development. The concepts taught are simple and understandable and practical in every way. The concept of upgrading from simpler technologies to slightly more complex ones forms the underlying theme of this approach to low cost and affordable sanitation. The children are able to gain "hands on" personal experience of toilets which form part of the "sanitation ladder."

\section{Acknowledgements}

We are most grateful for the support and encouragement given by the Sida supported Ecosanres programme, based in the Stockholm Environment Institute in Sweden. We particularly thank Madeleine Fogde and Arno Rosemarin and the SEI staff for their encouragement and support. We wish also to thank the Headmaster, Mr Mutisi and his dedicated staff and the children for the full cooperation and enthusiasm they have shown to support this project.

\section{References}

Morgan, Peter R. (1990). Rural Water Supplies and Sanitation. MACMILLAN. London. Morgan, Peter R. (2007). Toilets that make Compost. Stockholm Environment Institute.

\section{Contact details}

Annie Shangwa and Peter R. Morgan

Aquamor Pvt Ltd, PO Box MP1162, Mount Pleasant, Harare.

Email: Mrs Annie Shangwa: awesome@fastermail.com

Peter Morgan: petlin04@yahoo.com 